\title{
Effect of Video Games on the Adverse Corollaries of Chemotherapy at Pediatric Oncology Patients
}

\author{
Jihan Mahmoud Farrag', Amirat Ali Elsabely Mohammed ${ }^{2}$ \& Manal Mohamed Ahmed Ayed $^{3}$ \\ 1. Lecturer of Pediatric Nursing Department, Faculty of Nursing, PortSaid University, Egypt. \\ 2. Lecturer of Pediatric Nursing Department, Faculty of Nursing, Zagazig University, Egypt \&Assistant professor of \\ Pediatric Nursing College of Applied Medical Sciences Prince Sattam Bin Abdulaziz University, Saudi Arabia. \\ 3. Assistant Professor of Pediatric Nursing Department, Faculty of Nursing, Sohag University, Egypt.
}

\begin{abstract}
:
Chemotherapy causes many acute side effects. Video games distraction is a method that helps in relieving adverse corollaries. Aim: To investigate the effect of video games on the adverse corollaries of chemotherapy at pediatric oncology patients. Design: A quasi-experimental research design was utilized. Subjects: - A convenient sample of 100 children suffering from cancer undergoing chemotherapy was equally assigned into two groups the video games group (50 children) and the control group (50 children). Setting: the study was applied at the pediatric department at the Oncology Institute at Sohag City and Sohag University Hospital. Tools: Two tools were used (1) demographic characteristics tool and (2) Rhodes Index of Nausea and Vomiting Likert scale. Results: Regarding items of Rhodes index of nausea \&vomiting scale, it was found that all pediatric oncology patients (100\%) in the video games group had no nausea compared to slightly more than three quarters in the control group. Conclusion: Pediatric oncology patients undergoing chemotherapy who received video games had experienced lower intensity of nausea and vomiting compared to children in the control group. Recommendations: Pediatric nurses should involve video game in routine care among pediatric oncology patients undergoing chemotherapy to reduce and manage side effects of chemotherapy.
\end{abstract}

\section{Keywords: Adverse corollaries of chemotherapy, Pediatric oncology patients \& Video games.}

\section{Introduction}

Childhood cancer is still a big problem because; children's cancer can't be treated exactly like adult cancers where most of federal research funding goes. Current treatments are toxic, affect a child's development and can be decades old. To treat childhood cancer in the best way possible, we must create specialized treatment just for kids. The causes of childhood cancer are largely unknown (Kashaninia, 2016).

Cancer is treated with chemotherapy; chemotherapy is given in cycles, with each period of treatment followed by a rest period to give the body time to recover from the effects of the drugs. Cycles are most often 2 or 3 weeks long. Chemotherapy begins on the first day of each cycle, but the schedule varies depending on the drugs used (American Cancer Society, 2015). Moreover, Chemotherapeutic agents can be divided into several classes based on mechanism of action, chemical structure, biologic source, or effect on the cell cycle the nurse must be able to help the child to assume a comfortable position, provide emotional support, and explain the actions to be taken. The nurse should also teach the patient relaxation techniques and instruct him/ her to exercise hand with a rubber ball daily between treatments. This aids in vein development to dilate the veins (Heinemann \& Boyce, 2017).

Chemotherapy causes many distressing acute side effects. Video games distraction is a simple method that helps in relieving these problems, it occurs in up to $80 \%$ of pediatrics (National Cancer Institute, 2017).

Distraction is an effective technique that makes children's attention away from noxious stimuli and it includes several methods. By these methods, pleasant things deflect attention from medical procedures and reduce the perception of pain; this method is much less expensive than drug therapy (Bergomi et al., 2018).

Distraction methods include visual distraction (counting objects, watching TV), vocal distraction (listening to music), touch motion distraction (slow regular breathing), drawing, and purposive distraction (using toys). Other interventions include relaxation, hypnosis, modeling, desensitization, contingency management, selective attention, stress inoculation, cognitive restructuring, and coping skills training (Abd El-Gawad \& Elsayed, 2015).

Video game is considered an effective empowermentpromoting tool by improving one understands of health, disease, and treatment options. 
Video games show potential for health-related behavioral change by promoting disease education and self-management. Children with cancer who played Re-Mission, a sedentary video game designed to improve disease education and therapy compliance, showed improved mood, cancer-related knowledge, and chemotherapy adherence (Kato et al., 2018).

An audio-visual distraction like video games distraction is a simple method that helps nurses to solve the problem of lack of attention that diverts attention from a noxious stimulus through passively redirecting the subject's attention (Govender et al., 2017). Video games distraction direct concentration to other and take the attention away from own pain and concentrate on concern for someone else, more positive thoughts and distract with other sensations i.e. video games distraction can jog emotions and break the connection between the person and his/her emotional pain (Kaheni et al. 2016).

\section{Significance of the study:}

Cancer causes negative effects on children, there are many activities to help children with cancer undergoing chemotherapy experience good feelings and making them feel happy and relaxed. There is a lack of studies that discuss the importance of video games, drawing, and story-telling on improving children's happiness and relaxation during chemotherapy. So, the current study was to investigate the effect of video games, drawing, and story-telling on happiness and relaxation among children undergoing chemotherapy.

Nausea and vomiting are the most common and unpleasant side effects of chemotherapy, they may interfere with patient compliance to treatment completion and may be associated with considerable health care resource utilization (Burke et al. 2016). In association with traditional use of antiemetics for control of nausea and vomiting, it is necessary to find other methods for better control of side effects (Mazlum et al., 2017). There is a lack of studies which discuss the importance of video games as types of distraction on pediatric oncology patients undergoing chemotherapy, so that the current study was aimed to investigate the effect of video games on the adverse corollaries of chemotherapy in pediatric oncology patients.

\section{Aim of the study:}

To investigate the effect of video games on the adverse corollaries of chemotherapy at pediatric oncology patients

\section{Research hypothesis:}

Pediatric oncology patients undergoing chemotherapy who will received video games will have significantly lower intensity and frequency of nausea and vomiting compared with those in the control group.

\section{Subjects and Method:}

Research design:

A quasi-experimental research design was utilized to achieve the aim in the present study. Quasiexperimental research is a research design in which patients self-select or are selected into one of some different treatment groups to compare the real effectiveness and safety of non-randomized treatments (Maciejewski, 2020).

\section{Setting:}

The study was applied at the pediatric department in the Oncology Institute at Sohag city and Sohag University Hospital. These settings were selected because it receive large number of children with cancer and also it serves the biggest region of population from both rural and urban areas.

\section{Subjects:}

A convenient sample of 100 Pediatric oncology patients undergoing chemotherapy were recruited from the previously mentioned setting during six months from $1^{\text {st }}$ of July 2019 to the end of December 2019, were equally and randomly assigned into two groups, the first was the control group (50 children) who received only usual routine care and the second was the study group who received video games with chemotherapy treatment (50 children).

\section{The inclusion criteria were:}

1.Pediatric oncology patients undergoing chemotherapy, aged from 6-12 years and both sex.

2.Conscious.

3.Able to participate in the study and cooperative.

\section{Exclusion criteria}

1.Pediatric oncology patients under the effect of any anticonvulsant or analgesic drug.

2.Pediatric oncology patients who are critically ill.

Tools of data collection:

Tool (I): demographic characteristics tool was developed by the researchers after reviewing the related literature in addition to medical history of the child about cancer; it included two parts as the following:

Part 1: It included 3 questions regarding the demographic characteristics of children as age, gender, and residence

Part 2: It included five questions regarding the medical history of the studied children about cancer which included child's diagnosis, family history of cancer, duration of the disease, chemotherapy treatment methods, the side effects of chemotherapy such as, nausea, vomiting, joint pain, oral ulcer, headache, anorexia......etc.

Tool (2): Rhodes Index of Nausea and Vomiting Likert scale:

This tool was adopted by Rhodes and McDanial, (1999), it used to assess nausea and vomiting for children receiving chemotherapy, as the number of 
vomiting episodes per day, the quality and quantity of vomiting, degree and length of nausea. The constructed tool has 24 items, include 3 parts, the first part assess anticipatory nausea and vomiting and contain 8 items, the second part assess acute nausea and vomiting which contain 8 items and third part assess delayed nausea and vomiting which contain 8 items captures all the characteristics of nausea and vomiting. Internal consistency was tested by using Cronbach's alpha and it was 0.97 .

Scoring system:

- For the questions that have "yes" or "no" answer, "yes" was assigned a value of "1", and " no" was assigned a value of " 0. ."

- For questions asking about the duration of nausea, if the duration is less than one hour, the score is " 1 ", if the duration is more than one hour, the score is " 2. ."

- For the questions asking about the severity of nausea and vomiting, mild was assigned a value of "1", moderate was assigned a value of "2", severe was assigned a value of " 3 ", and intolerable was assigned a value of " 4 ."

- For the questions asking about the frequency of nausea and vomiting, "once" was assigned a value of " 1 ", "twice" was assigned a value of " 2 " and so on.

- For the questions asking about the estimation of the amount of vomiting, "small amount" was assigned a value of "1", "moderate amount" was assigned a value of "2", and "large amount" was assigned a value (Rhodes \& McDaniel, 1999).

\section{Tools validity:}

Content validity of the tools was determined and the content of the data collection tools was submitted to a panel of five experts in Pediatric Nursing and Pediatric Oncology with more than ten years of experience in the field. Modifications of the tools were done according to the panel judgment on the clarity of sentences, appropriateness of the content, sequence of items, and accuracy of scoring and recording of the items, and Validity index was $97 \%$.

\section{Tool Reliability}

Tools reliability was tested using internal consistency methods (Alpha Cronbach's test for the first tool, its result was 0.89 which indicates good reliability of the tool. Internal consistency of Rhodes scale was tested by using Cronbach's alpha and it was 0.97 . The content reliability index was 0.88 .

Method of data collection:

Before starting this study, administrative permission was obtained from the Dean of the Faculty of Nursing Sohag University. Administrative approval was obtained from managers in the previously mentioned setting.

A pilot study was carried out on $10 \%$ of the studied pediatric oncology patients (10), for modification clarification and estimation of the time needed for filling the study tools and testing the feasibility of the research process. The unclear items were clarified, unnecessary items were omitted and new items were added. Those who shared in the pilot study were excluded from the study sample.

\section{Procedure of data collection:}

Data was collected within six months from $1^{\text {st }}$ of July 2019 to the end of December 2019. Data collection was done during the routine work of the previous selected settings. Researchers attended the previously mentioned settings for data collection two days each week from 9.00 a.m. to 1.00 p.m.

- Implementation of the study included three phases (assessment phase, implementation phase, and evaluation phase).

\section{Assessment phase:}

An explanation was done about the aim and content of the study. Participants of both groups were asked to fill the questionnaires by researchers assistant which include (demographic data, medical data, and Rhodes Index of Nausea and Vomiting Likert scale). The participants took about 50-60 minutes to fulfill the questionnaire and the other used tool was completed by the researchers.

\section{Implementation Phase: \\ For study group:}

In the video games group, the researchers interviewed each pediatric oncology patients individually for about 30 minutes; the researchers introduced themselves to them and explained the aim of the study as well as oral consent was obtained from them then demographic and nausea and vomiting incidences were documented during and after chemotherapy by using Rhodes index for nausea and vomiting Scale were collected from the pediatric oncology patients with using of the video games.

Video games were administered, through the researcher's laptop beside the routine care which contains funny and educational games for about 30 minutes during chemotherapy procedure, and continued throughout the procedure during which nausea and vomiting was assessed by using the selected tool by the researchers.

For control group:

In the control group, the researchers interviewed each pediatric oncology patients individually for about 30 minutes; the researchers introduced themselves to them and explained the aim of the study as well as oral consent was obtained from them then demographic and nausea and vomiting incidences were documented during and after chemotherapy by using Rhodes index for nausea and vomiting Scale were collected from the pediatric oncology patients without using of the video games. No practice other than the patients received routine hospital care (the standard care for pediatric 
patients undergoing chemotherapy in the ward consisted of drug administration according to doctor prescription, procedures, and nursing care to them normally given during chemotherapy).

Evaluation phase:

Children in both groups (the study and the control groups) were reassessed after the chemotherapy treatment by the researchers for the characteristics of nausea and vomiting such as (Number of vomiting episodes, duration of nausea, and frequency of nausea and vomiting) using Rhodes index for nausea and vomiting the same tool used in the pretest (tools II as post-test). The children were followed twice after receiving chemotherapy treatment after 12 hours and then after another 12 hours by using telephone call with their mothers.

\section{Ethical consideration:}

Written consent was obtained from the mothers of the children. The researchers explained to each child and his mother the aim and benefit of the study.
The mothers were informed that their participation is voluntary and had the ethical right to participates or refuse participation in the study and emphasized that their responses were confidential, and had their right to withdraw from the study any time without giving further explanation. Privacy and confidentiality were resolutely kept in all data collection procedures.

Statistical analysis:

Date entry and data analysis were done using SPSS version 19 (Statistical Package for Social Science). Data were presented as number, percentage, mean, median and standard deviation. Chi-square test and Fisher exact test were used to compare qualitative variables. Mann-Whitney test was used to compare quantitative variables between two groups. P-value considered statistically significant when $\mathrm{P}<0.05$.

\section{Results:}

Table (1): Distribution of the studied pediatric oncology patients in video games and control groups regarding their demographic characteristics $(n=100)$

\begin{tabular}{|c|c|c|c|c|c|c|}
\hline \multirow[t]{2}{*}{ Items } & \multicolumn{2}{|c|}{$\begin{array}{l}\text { Video games group } \\
(n=50)\end{array}$} & \multicolumn{2}{|c|}{$\begin{array}{c}\text { Control group } \\
(\mathbf{n}=\mathbf{5 0})\end{array}$} & \multirow{2}{*}{$\mathrm{X} 2$} & \multirow{2}{*}{ p-value } \\
\hline & No & $\%$ & No & $\%$ & & \\
\hline \multicolumn{7}{|l|}{$\overline{\text { Age }}$} \\
\hline $6-<8$ & 3 & 6 & 5 & 10 & \multirow{4}{*}{0.876} & \multirow{4}{*}{0.913} \\
\hline $8-<10$ & 28 & 56 & 25 & 50 & & \\
\hline $10-12$ & 19 & 38 & 20 & 40 & & \\
\hline$M \pm S D$ & \multicolumn{2}{|c|}{$8.59 \pm 1.73$} & \multicolumn{2}{|c|}{$8.63 \pm 1.93$} & & \\
\hline \multicolumn{7}{|l|}{ Gender } \\
\hline Boys & 29 & 58 & 32 & 64 & \multirow[t]{2}{*}{0.654} & \multirow[t]{2}{*}{0.671} \\
\hline Girls & 21 & 42 & 18 & 36 & & \\
\hline \multicolumn{7}{|l|}{ Residence: } \\
\hline Urban & 31 & 62 & 30 & 60 & \multirow[t]{2}{*}{0.756} & \multirow[t]{2}{*}{0.289} \\
\hline Rural & 19 & 38 & 20 & 40 & & \\
\hline
\end{tabular}

N.S: Not significant

Table (2): Distribution of the studied pediatric oncology patients in video games and control groups regarding their medical diagnosis $(n=100)$

\begin{tabular}{|c|c|c|c|c|c|}
\hline \multirow[t]{2}{*}{ Diagnosis } & \multicolumn{2}{|c|}{$\begin{array}{c}\text { Video games group } \\
(n=50)\end{array}$} & \multicolumn{2}{|c|}{$\begin{array}{c}\text { Control group } \\
(n=50)\end{array}$} & \multirow[t]{2}{*}{ P-value } \\
\hline & No & $\%$ & No & $\%$ & \\
\hline Kidney tumor & 3 & 6 & 7 & 14 & 0.837 N.S \\
\hline Brain tumor & 4 & 8 & 3 & 6 & 0.789 N.S \\
\hline Leukemia & 23 & 46 & 20 & 40 & 0.316 N.S \\
\hline Pelvic tumor & 8 & 16 & 9 & 18 & 0.708 N.S \\
\hline Thyroid tumor & 11 & 22 & 8 & 16 & 0.201 N.S \\
\hline Pulmonary Tumor & 1 & 2 & 3 & 6 & 0.211 N.S \\
\hline
\end{tabular}

N.S: Not significant 
Table (3): Distribution of the studied pediatric oncology patients in video games and control groups regarding their medical data $(n=100)$

\begin{tabular}{|c|c|c|c|c|c|}
\hline \multirow{2}{*}{ Items } & \multicolumn{2}{|c|}{ Video games group $(n=50)$} & \multicolumn{2}{|c|}{ Control group $(n=50)$} & \multirow[b]{2}{*}{ p-value } \\
\hline & No & $\%$ & No & $\%$ & \\
\hline \multicolumn{6}{|c|}{ Family history of cancer } \\
\hline Yes & 19 & 38 & 22 & 44 & \multirow[t]{2}{*}{0.185} \\
\hline No & 31 & 62 & 28 & 56 & \\
\hline \multicolumn{6}{|c|}{ Duration of disease in years } \\
\hline 1 year & 33 & 66 & 37 & 74 & \multirow[t]{3}{*}{0.176} \\
\hline 2 years & 11 & 22 & 9 & 18 & \\
\hline 3 years or more & 6 & 12 & 4 & 8 & \\
\hline \multicolumn{6}{|c|}{ Type of chemotherapy as a treatment: } \\
\hline Infusion & 33 & 66 & 32 & 64 & \multirow[b]{2}{*}{$0.02 *$} \\
\hline Infusion + IM & 17 & 34 & 18 & 36 & \\
\hline \multicolumn{6}{|c|}{ Side effects of chemotherapy pre intervention: } \\
\hline Nausea & 30 & 60 & 29 & 58 & 0.495 \\
\hline Vomiting & 49 & 98 & 50 & 100 & 0.593 \\
\hline Oral ulcer & 28 & 56 & 26 & 52 & 0.694 \\
\hline Joint pain & 28 & 46 & 26 & 52 & 0.795 \\
\hline Anorexia & 29 & 58 & 32 & 64 & 0.892 \\
\hline Headache & 18 & 36 & 16 & 32 & 0.895 \\
\hline Drowsiness & 8 & 16 & 7 & 14 & 0.834 \\
\hline General weakness & 11 & 22 & 12 & 24 & 0.775 \\
\hline Constipation & 4 & 8 & 3 & 6 & 0.893 \\
\hline Stomachache & 3 & 6 & 2 & 4 & 0.695 \\
\hline Alopecia & 3 & 6 & 4 & 8 & 0.872 \\
\hline
\end{tabular}

Table (4): Distribution of pediatric oncology patients according to items of Rhodes index of nausea and vomiting scale during anticipatory nausea and vomiting $(\mathbf{n}=100)$

\begin{tabular}{|c|c|c|c|c|c|}
\hline \multirow{2}{*}{ Items } & \multicolumn{2}{|c|}{ Video games group $(n=50)$} & \multicolumn{2}{|c|}{ Control group $(\mathrm{n}=50)$} & \multirow{2}{*}{ P-value } \\
\hline & $\overline{\mathrm{No}}$ & $\%$ & No & $\%$ & \\
\hline \multicolumn{5}{|c|}{ Nausea before last chemotherapy treatment: } & \multirow{3}{*}{1.000} \\
\hline Yes & 16 & 32 & 14 & 28 & \\
\hline No & 34 & 68 & 36 & 72 & \\
\hline \multicolumn{5}{|c|}{ Duration of nausea (hrs): } & \multirow{2}{*}{0.294} \\
\hline Mean \pm SD & \multicolumn{2}{|c|}{$4.45 \pm 4.00$} & \multicolumn{2}{|c|}{$4.67 \pm 3.60$} & \\
\hline \multicolumn{5}{|c|}{ Severity of nausea at its worst: } & \multirow{4}{*}{0.553} \\
\hline Mild & 5 & 10 & 10 & 20 & \\
\hline Moderate & 4 & 8 & 3 & 6 & \\
\hline Severe & 41 & 82 & 37 & 74 & \\
\hline \multicolumn{5}{|c|}{ Number of nausea episodes } & \multirow{2}{*}{0.653} \\
\hline Mean \pm SD & & \pm 1.22 & & & \\
\hline \multicolumn{5}{|c|}{ Vomiting before last chemotherapy treatment: } & \multirow{3}{*}{0.579} \\
\hline Yes & 40 & 80 & 39 & 78 & \\
\hline No & 10 & 20 & 11 & 22 & \\
\hline \multicolumn{5}{|c|}{ Severity of vomiting at its worst: } & \multirow{4}{*}{0.783} \\
\hline Mild & 45 & 90 & 46 & 92 & \\
\hline Moderate & 2 & 4 & 2 & 4 & \\
\hline Severe & 3 & 6 & 2 & 4 & \\
\hline \multicolumn{5}{|c|}{ Number of vomiting episodes } & \multirow{2}{*}{$0.865^{*}$} \\
\hline Mean \pm SD & & $1.51 \pm 1.03$ & & & \\
\hline \multicolumn{5}{|c|}{ Amount of the vomiting before treatment: } & \multirow{4}{*}{$0.778^{*}$} \\
\hline Small & & 90 & 47 & 94 & \\
\hline \multicolumn{2}{|l|}{ Moderate } & 6 & 2 & 4 & \\
\hline \multicolumn{2}{|l|}{ Large } & 4 & 1 & 2 & \\
\hline
\end{tabular}

*highly Significance differences 
Table (5): Distribution of pediatric oncology patients according to items of Rhodes index of nausea and vomiting scale during acute nausea and vomiting $(n=100)$

\begin{tabular}{|c|c|c|c|c|c|}
\hline \multirow{2}{*}{ Items } & \multicolumn{2}{|c|}{ Video games group $(n=50)$} & \multicolumn{2}{|c|}{ Control group $(n=50)$} & \multirow{2}{*}{ P-value } \\
\hline & No & $\%$ & No & $\%$ & \\
\hline \multicolumn{5}{|c|}{ Nausea during or within 24 hours of last chemotherapy treatment: } & \multirow{3}{*}{$0.000 *$} \\
\hline Yes & 0 & 0.0 & 12 & 24 & \\
\hline No & 50 & 100 & 38 & 76 & \\
\hline \multicolumn{5}{|c|}{ Vomiting during or within 24 hours of last treatment: } & \multirow{3}{*}{$0.000 *$} \\
\hline Yes & 2 & 4 & 50 & 100 & \\
\hline No & 48 & 96 & 0 & 0.0 & \\
\hline \multicolumn{5}{|c|}{ Severity of vomiting at its worst: $n=2-$} & \multirow{5}{*}{0.558} \\
\hline Mild & 0 & 0.0 & 41 & 82 & \\
\hline Moderate & 2 & 100 & 2 & 4 & \\
\hline Severe & 0 & 0.0 & 7 & 14 & \\
\hline Intolerable & 0 & 0.0 & 0 & 0.0 & \\
\hline \multicolumn{5}{|c|}{ Number of vomiting episodes during or within 24 hours of treatment: } & \multirow{2}{*}{0.845} \\
\hline Mean \pm SD & & & & & \\
\hline \multicolumn{5}{|c|}{ Amount of the vomiting: } & \multirow{4}{*}{0.504} \\
\hline Small & 0 & 0.0 & 38 & 76 & \\
\hline Moderate & 2 & 100 & 4 & 6 & \\
\hline Large & 0 & 0.0 & 8 & 16 & \\
\hline
\end{tabular}

*Highly Significance differences

Table (6): Distribution of children in study and control group according to items of Rhodes index of nausea and vomiting scale during delayed nausea and vomiting during 24 hour or more of last chemotherapy treatment

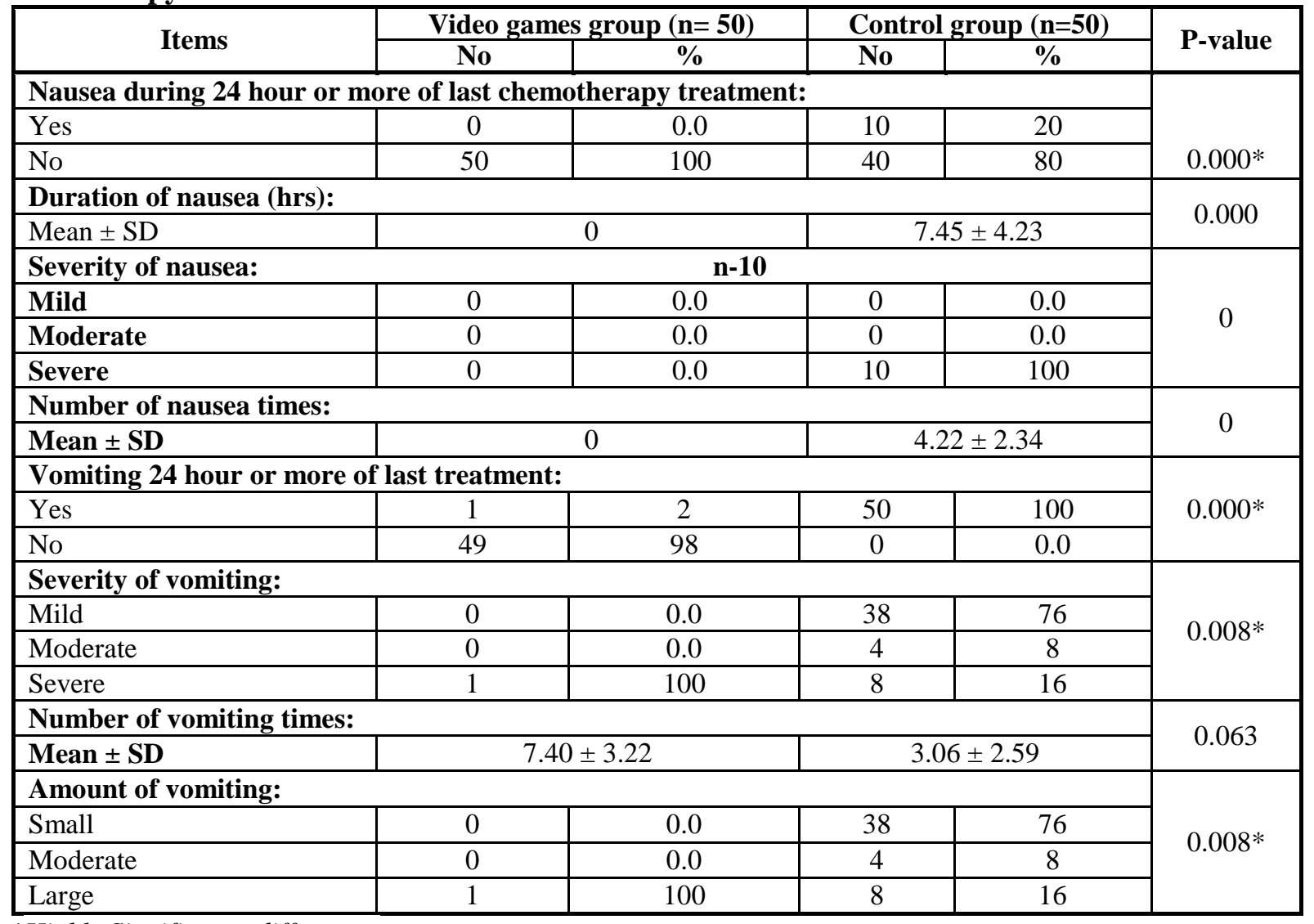

*Highly Significance differences 
Table (7): Distribution of the studied pediatric oncology patients pre and post video games intervention $(\mathbf{n}=50)$

\begin{tabular}{|c|c|c|c|c|c|}
\hline \multirow[t]{2}{*}{ Items } & \multicolumn{2}{|c|}{$\begin{array}{l}\text { Pre video games group } \\
\qquad(\mathrm{n}=\mathbf{5 0})\end{array}$} & \multicolumn{2}{|c|}{$\begin{array}{l}\text { Post video games group } \\
\qquad(\mathrm{n}=\mathbf{5 0})\end{array}$} & \multirow[t]{2}{*}{ p-value } \\
\hline & No & $\%$ & No & $\%$ & \\
\hline Nausea & 30 & 60 & 0 & 0.0 & $0.000^{*}$ \\
\hline Vomiting & 49 & 98 & 1 & 2 & $0.000^{*}$ \\
\hline
\end{tabular}

*Highly Significance differences

Table (1): Illustrated that (56\%) and (50\%) of children who received video games and those in the control groups their age were ranged from $8<10$ years with mean \pm SD $(8.59 \pm 1.73$ and $8.63 \pm 1.93$ respectively). Boys were most prominent in video games and control groups $(58 \%$ and 64\% respectively). As regard residence $(62 \%)$ and $(60 \%)$ of children who received video games and control groups were living in urban areas respectively. no statistically significant differences were found between children in the study and the control group regarding their demographic characteristics.

Table (2): Portrayed the medical diagnosis of children in in both video games, and control groups. The results demonstrated that no statistically significant difference was found between both groups' different diagnoses such as a brain tumor, kidney tumor, leukemia, pelvic tumor, thyroid tumor, and pulmonary tumor. It was noticed that leukemia was mostly frequently found between children among children who received video games and control groups (46\%) and (40\%) respectively.

Table (3): Demonstrated medical data among children in the studied and control groups and it indicated that approximately two thirds $(62 \%)$ of the video games group compared to more than half $56 \%$ of the control group had no family history of cancer. it was observed that $(66 \%)$ and $(74 \%)$ of children in video games and control groups had cancer for one year respectively. The results also, illustrated (66\%) and $(64 \%)$ of children in video games and control groups were treated with infusion methods with statistically significant difference at $(\mathrm{p}=0.02 *)$. As regards to side effect of chemotherapy the results in the same table also observed that nausea was constituted high percentage of side effects $(60 \%$ and $58 \%$ respectively) among children in video games and control group, and vomiting was $(98 \%$ and $100 \%$ respectively) as a result of chemotherapy administration among children.

Table (4): Illustrated that $(68 \%$ and $72 \%)$ of the video games and control groups respectively had no nausea before their last chemotherapy treatment. As regards the duration of nausea, the Mean \pm SD were $4.45 \pm 4.00$ for the video games group compared to
$4.67 \pm 3.60$ for the control group. Additionally, the same table indicated that $(10 \%$ compared to $20 \%$ respectively of the both groups had mild type of nausea. There were no a statistically significant differences between the video games \& control groups regarding number of nausea per 24 hours with mean \pm SD $(1.51 \pm 1.03$ compared to $2.69 \pm 1.09$ respectively. Also, the table showed that no a statistically significant differences were found between the video games and control groups concerning amount of the vomiting before treatment.

Table (5): Demonstrated percentage distribution of pediatric oncology patients according to items of Rhodes index of nausea \&vomiting scale during acute nausea \& vomiting the table found that all pediatric oncology patients $(100 \%)$ in the video games group had no nausea compared to $(76 \%)$ in the control group with statistically significant differences $(\mathrm{p}=0.000)$. almost pediatric oncology patients in the video games group $(96 \%)$ compared to $(0.0 \%)$ in the control group had no vomiting during or within 24hours of their last treatment and also a statistically significant differences was observed between the two groups according to vomiting during or within 24 hours of their last treatment $(\mathrm{p}=0.00 \%)$. No statistically significant differences were detected between the two groups as regarding severity, number and amount of vomiting.

Table (6): Showed the distribution of pediatric oncology patients according to items of Rhodes index of nausea and vomiting scale during delayed nausea \&vomiting. It observed that $(100 \%$ compared to $80 \%$ respectively) in the video games and control groups had no nausea during 24 hours or more of chemotherapy treatment. Also the majority of pediatric oncology patients in the video games group $(98 \%)$ compared to $(0.0 \%)$ of children in the control group had no vomiting with a statistically significant difference was found between the video games and control groups regarding the presence of vomiting $\mathrm{p}=$ (0.000).

Table (7): Illustrated the distribution of pediatric oncology patients pre and post video games intervention, it was observed decreased in the amount and frequency of nausea and vomiting, where pre video games intervention percentage of children with 
nausea was $(60 \%)$ and become 0 post intervention. Regarding vomiting percentage of children with nausea was $(98 \%)$ and become (2\%) post intervention.

\section{Discussion:}

Chemotherapy causes many side effects from these are nausea and vomiting which, considered from the most distressing and feared side effect of chemotherapy experienced by pediatric oncology patients. It is estimated that between $60-80 \%$ of pediatric oncology patients who are receiving chemotherapy experienced nausea and vomiting (Kashaninia, 2016). Distraction is considered the most effective procedure to decrease incidence of nausea and vomiting during routine care. So, the study aimed to investigate the effect of video games on the adverse corollaries of chemotherapy in pediatric oncology patients.

The results of the present study revealed that males were most prominent in video games and control groups. These results are similar to conducted by Mohamed et al., (2021) who studied Effect of Video Games, Drawing and Story-Telling on Happiness and Relaxation among Children Undergoing Chemotherapy and reported that males were most prominent in the two groups. The results are in the same line with the results done by the Worldwide Organization, (2016) which stated that the cancer incidence in male was higher than female. Also, these findings are matched with El Sayed et al., (2019), who studied the "Effect of Story-Telling on Reducing the Intensity of Nausea and Vomiting among Children Undergoing Chemotherapy", and reported the same results.

The result of the present study indicated that that leukemia was mostly frequently found between children in all groups. This finding is agree with result in a study performed by Abdel Hadi, (2017) who studied comprehensive care in pediatric oncology patients and reported that acute lymphatic leukemia was the most common type of cancer in children, and El Sayed et al., (2019) also, found that leukemia was most frequent among pediatric oncology patients. Also the result is in same line with Elatter et al., (2018) who investigated cancer statistics, and observed that the most common type of cancer was leukemia.

The results of the current study revealed that more than two-thirds of children in video games group and less than three-quarters of children in control group had cancer for one year ago. This finding is in the same line with the study performed by Hassan, (2015) who studied "Effect of Guided Imagery Relaxation Session and Story-Telling on the Intensity of Nausea and Vomiting among Children Undergoing
Chemotherapy" and noticed that approximately onehalf of children had cancer for less than 6 months. Similarly, Abd El Razik (2017) who studied "Effect of Educational Program on Quality of life for patients with cancer undergoing chemotherapy" and reported that more than two-thirds of children developed cancer for less than one year. This is reflected delayed discovery of cancer among the young age of children. The present study indicated that approximately two thirds of children in the video games group compared to more than half of them in the control group had no family history of cancer. This is explained by the early life exposure to infectious agents, fetal or childhood exposure to environmental toxin such as pesticides, solvents, or other household chemicals, or radiation.

The results of the current study showed that approximately two thirds of children in the video games group and less than two-thirds of children in the control group were treated with infusion methods. These results are supported by the results done by Hassan, (2015) who found in his study in Tanta city that treatment was administered for children intravenously. Also, these finding was in congruence with Mohamed et al., (2021) who stated that the majority of children received chemotherapy through and treated with infusion methods.

The current results indicated that were constituted high percentage of side effects as a result of chemotherapy administration among children in both groups. From the researchers' point of view, this result related to the toxicity of chemotherapy drug and the harmful effects on normal cells as well as cancer cells.

The results of the current study indicated that there were a statistically significant differences and decreasing number of nausea per 24 hours between children in the video games \&those in the control groups regarding. This may be due to children's attention was occupied by distraction technique activation and decreased in the areas of the brain (Martin, 2018).

Also, similar to the study conducted by Cerne et al. (2018) who studied " Effectiveness of Cartoons as a Distraction Child Health Care " and found that procedures in oncology departments and distraction technique before and during procedures very effective and important because it is cheap and easily available, require less staff number and accepted by the pediatric oncology patients and their families and there is no harm to them and it can increase pediatric oncology patients participation and improve their coping.

The current study revealed that all pediatric oncology patients $(100 \%)$ in the video games group had no nausea compared to more than three quarters in the 
control with statistically significant differences ( $\mathrm{p}=0.000$ ) within 24 hours of their last treatment. This reflected the positive effects of using video games in reducing on the adverse corollaries of chemotherapy among pediatric oncology patients. This finding was similar to a study done by Hassan, (2015) who found that more than half of children in the study groups developed nausea \& vomiting before conducting distraction techniques.

Regarding items of Rhodes index of nausea and vomiting scale during delayed nausea \&vomiting among pediatric oncology patients. The current study results revealed that all and the majority of pediatric oncology patients in the video games and control groups respectively had no vomiting during 24 hours or more of chemotherapy treatment. These results are agreed with Roy, (2016) who studied "Psychological Intervention with chemotherapy patients "and indicated that video game reduced nausea and vomiting. This could be due to distraction induced by video game. This is related to children's attention that was occupied by distraction task activation and reduced in the areas of the brain that were responsible for the occurrence of nausea and vomiting such as thalamus, insula , and the anterior cingulated cortex (Martin, 2018).

The results of the present study revealed decreasing in the amount and frequency of nausea and vomiting of pediatric oncology patients pre and post video games intervention, from the researchers point of view, it reflects the positive effects and success of intervention in revealed decreasing in the amount and frequency of nausea and vomiting of pediatric oncology patients.

\section{Conclusion:}

The current study concluded based on the results and study hypothesis that pediatric oncology patients undergoing chemotherapy who received video games had experienced lower nausea and vomiting compared to children in the control group who received routine hospital care only.

\section{Recommendations:}

In the light of the findings obtained from the current study the following recommendations were suggested:

- Pediatric nurses should be involved video game in routine care among pediatric oncology patients undergoing chemotherapy to reduce and manage side effects of chemotherapy.

- Parents' education about video games as distraction techniques for pediatric oncology patients.

- Equipment that needed and used for distraction techniques should be available at the hospitals such as toys, attractive books, puppets, video games, bubbles, and drawing equipment as a sketch and colored pencils for drawing that distracts the children and hold their attention.

\section{References:}

- Abdel Hadi, S. (2017): Comprehensive care in pediatric cancer patient, Pediatric oncology NCI, Egypt.

- Abd El Razik, S. (2017): Effect of educational program on quality of life for patients with cancer undergoing chemotherapy, doctoral Degree, Faculty of Nursing, Benha University, PP: 30-35.

- Abd El-Gawad, S. \& Elsayed, L. (2015): Effect of interactive distraction versus cutaneous stimulation for venipuncture pain relief in school-age children. Journal of Nursing Education and Practice, 5(4): 3240.

- American cancer society, (2015): Cancer facts and figures -.A Gide for patient Atlanta; American cancer society Inc. Retrieved from: http//www.cancer.org/Pdf.

- Bergomi, P., Scudeller, S., Pintaldi, A., \& Dal, M. (2018): Efficacy of non-pharmacological methods of pain management in children undergoing venipuncture in a pediatric outpatient clinic: A Randomized Controlled Trial of Audiovisual Distraction and External Cold and Vibration, Journal of Pediatric Nursing 42. May, DOI: 10.1016/j.pedn.2018.04.011

- Burke, T., Wisniewski, T., \& Ernst, F. (2016): Resource utilization and costs associated with chemotherapy-induced nausea and vomiting following highly or moderately emetogenic chemotherapy administered in the US outpatient hospital setting. Support Care Cancer, 19 (1): 13140.

- Cerne, D., Sannino, S., \& Petean, M. (2018): Participation in the care of a hospitalized child: A Randomized Controlled Trial Examining the perspective from a developing country, Effectiveness of Cartoons as a Distraction Child Health Care. Online publication DOI: Technique. Nurs Child Young People, 27(3): 28-33. 10.1177/136749351559865.

- El Sayed, S., Ibrahim, H., Thabet M., \& Mohamed A.M. (2019): Effect of story-telling on reducing the intensity of nausea and vomiting among children undergoing chemotherapy, Article 17, Volume 7, Issue 17, Spring 2019, Page 164-172. DOI: 10.21608/ASNJ.2019.56979.

- Elatter, S., \& Ibrahim, S. (2018): Cancer Statistics, Department of Biostatstics \& Epidemiology .Retrieved from www.cancer.gov.eg

- Govender, M., Bowen, R.C., German, M.L., Bulaj, G., \& Bruggers, C.S. ((2017): Clinical and neurobiological perspectives of empowering 
pediatric cancer patients using videogames. Games Health J 4:362-74. Doi: 10.1089/ g4h.2015.0014

- Hassan, A. (2015): Effect of Guided Imagery Relaxation Session and Story-Telling on the Intensity of Nausea and Vomiting among Children Undergoing Chemotherapy, doctoral Degree, Nursing, Tanta University.

- Heinemann, K. \& Boyce, A. (2017): Emergencies in pediatric oncology. Therapeutic drugs. Chapter 13. Springer. New York, Pp. 105-106.

- Kaheni, S., Rezai, M., Bagheri, M., \& Goudarzian, A. (2016): The Effect of distraction technique on the pain of dressing change in Kahani et al. Int J Pediatr, Vol.4, N.5, Serial No.29, May 1801 3-6-Year-old Children. International Journal of Pediatrics; 4(4):1603-10.

- Kashaninia, A. (2016): Clinical characteristics associated with the development of anticipatory nausea and vomiting in patients with cancer undergoing chemotherapy treatment, Journal of Clinical Oncology, 94(8) 421- 446.

- Kato, P.M., Cole, S.W., Bradlyn, A.S., \& Pollock, B.H. (2018): A video game improves behavioral outcomes in adolescents and young adults with cancer: a randomized trial. Pediatrics 122:e305-17. Doi: $10.1542 /$ peds. -3134

- Maciejewski, M. (2020): Quasi-Experimental design. Biostatistics \& Epidemiology; 4 (1): 38-47.

- Martin, A. (2018): Measuring chemotherapyinduced nausea and emesis. Cancer, 98(6):645-655.

- Mazlum, S., Toghian, N., Banihashem, A., \& Behnam, H. (2017): The effect of massage therapy on chemotherapy-induced nausea and vomiting in pediatric cancer, Iran Journal Nursing Midwifery Res, 18(4): 280-284.

- Mohamed, A., Sayed M., \& El-Sayed, F. (2021): Effect of Video Games, Drawing and Story Telling on Happiness and Relaxation among Children Undergoing Chemotherapy, International Journal of Novel Research in Healthcare and Nursing, Vol. 8, Issue 1, pp: (679-687).

- National Cancer Institute (2017): Nausea and Vomiting PDQ- 19 (1): 131-40.

- Rhodes, V., \& McDaniel, G. (1999): Nausea, Vomiting and retching the management of the symptoms experience. Seminar oncology nurse, 11(10):256-5

- Roy, S.M. (2016): "Psychological Intervention with chemotherapy patients: Evaluation Outcome. Journal of Advances in Psychosomatic Medicine, 15 (6):23-50.

- Worldwide organization (2016): Cancer priorities in developing countries. Annually Oncology, 12(8):112-120. Retrieved from www.globalhealth.org/cancer priorities in developing countries annually oncology, 12(8):1120120.retrieved from ww.globalhealth.org/ 